II $B$ and II cultures but still protects against II $A$ cultures. Hence, in terms of the protective substances in chicken serum, Types II $A$ and II $B$ are main groups with Type II as a subgroup to them both.

Fractionation of the serum by means of ammonium sulphate and dialysis showed that the protective substances adhere quantitatively to the water-insoluble globulin.

\title{
86 (1668)
}

A simple apparatus for studying the factors influencing fish migration.

BY F. E. CHIDESTER.

[From the West Virginia University, West Virginia.]

At the request of Dr. H. M. Smith, commissioner of fisheries, certain studies have been made at the Woods Hole Laboratory of the Bureau of Fisheries on the factors influencing fish migration.

In testing reactions to various salts a simple apparatus was devised that seems to eliminate some of the drawbacks of the well-known Shelford apparatus.

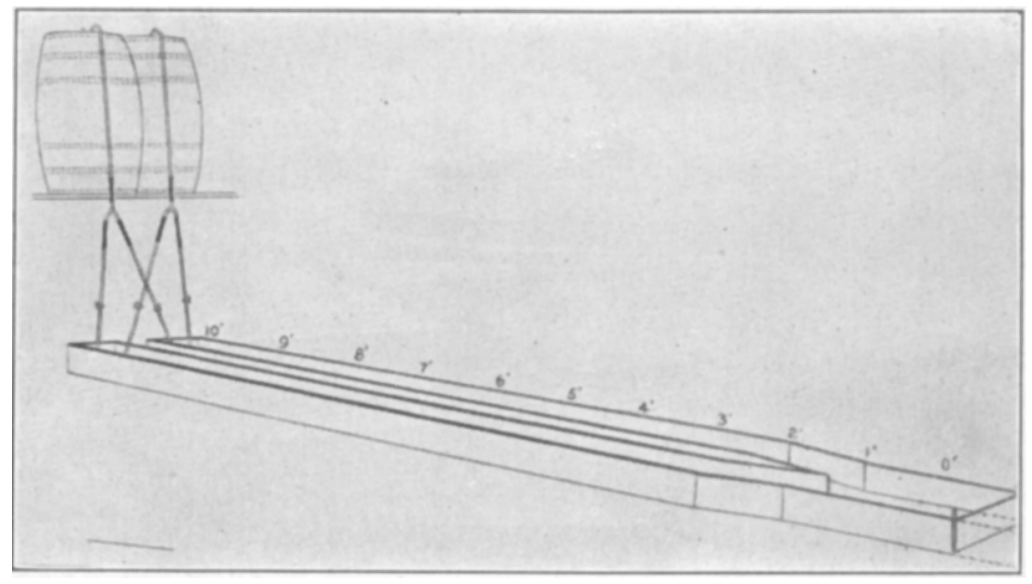

Fig. 1.

It consists (Fig. I) of two troughs running almost parallel into a large trough which has a movable partition permitting the 
water to escape at its sides. By a simple arrangement of stopcocks it is possible to change the inflow of any substance from one trough to the other very quickly. It is also possible to secure conditions similar to those in the Shelford apparatus by using an intake at the end of the large trough, thus furnishing three intakes, two of them parallel to each other. In this case the movable partition is not used, the outflow being in the middle of the larger trough.

The apparatus used during the summers of 1919 and 1920 is 20 feet long. The dimensions of the receiving trough are ro feet in length, 8 inches in depth and $83 / 4$ inches in width. The two tributary troughs are each to feet in length, 4 inches in depth and $4 \frac{1}{2}$ inches in wilth. The tributary troughs have been elevated varying degrees so as to cause the water to flow downwards into the receiving pool. In addition to the use of barrels as containers for the solutions used, in some experiments the inflow has been directly from the circulation pipes of the laboratory.

The fish used in the experiments included Fundulus heteroclitus, Fundulus majalis, and clupea harengus. They were tested with sea water of various dilution ind concentrations, $m /$ Io solutions of $\mathrm{NaCl}, \mathrm{KCl}, \mathrm{MgCl}_{2}, \mathrm{C}^{\mathrm{a}} \mathrm{Cl}_{2}, \mathrm{MgSO}_{4}$, various combinations of those salts and also with sewage polluted water. The temperature and the stream flow were varied in some of the experiments.

The results obtained indicate the following behavior:

I. The fish used in the experiments (Io fish for 25 trials) responded to both toxic and nontoxic substances, discriminating them readily under the same conditions of stream flow and temperature.

2. With a more attractive stream flow, usually one slightly more rapid than the control, the fish were lured into solutions that were quickly lethal in experimental jars. No evidence of intoxication in reactions to any particular substance was adduced. The reaction seemed to be onc of pure rheotaxis.

3. Temperature change was readily detected but the optimum temperature varies with the season and the physiological condition of the animal.

4. In experiments with the apparatus used, errors due to the reaction of the fishes to movements of the observer have been 
reduced by the arrangement of the observing post at the ends of two almost parallel troughs. The reaction of a fish to currents of water has also been considered in furnishing it control and experimental flows close together.

5. Habit formation has been studied by changing the control to the experimental trough after a series of trials with any of the substances.

$$
87 \text { (1669) }
$$

\section{Pharmacological examination of cinnamein, benzyl succinate and benzyl nitrite.}

By DAVID I. MACHT.

[From the Pharmacological Laboratory, Johns Hopkins University.]

The discovery of the interest ng pharmacological properties of benzyl benzoate and benzyl acetate first announced by the author in these Proceedings and the widespread therapeutic use of benzyl benzoate which immediately followed it, has naturally stimulated various observers to search for other benzyl compounds which might be available for clinical work. A number of such compounds have been since described, but none of these to the author's knowledge possessed together the two characteristics of benzyl benzoate, namely simplicity of chemical structure and efficiency of pharmacological action. The present author has also examined a number of benzyl preparations and found a majority of these unimportant in comparison with the original drug. In the present communication, however, it is proposed to describe briefly three benzyl preparations which have more than scientific interest in as much as at least two of these may be suitable for therapeutic application in special cases.

Benzyl benzoate is a synthetic compound, but is also found in nature and it has been suggested that for the production of the benzyl effect Cinnamein might be used. Cinnamein is a mixture of esters, alcohols and other substances obtained from the balsams of Peru and Tolu. Among these are benzyl benzoate and benzyl cinnamate. Cinnamein is a drug possessing a pleasant aromatic odor and bitterish taste and is anesthetic to the tongue and lips. 